\title{
INDICADORES PSICOSSOCIAIS: UM OLHAR AMPLIADO PARA PROCESSOS EDUCATIVOS
}

SANDRA LÚCIA FERREIRA ANAMÉRICA PRADO MARCONDES ADELINA NOVAES

\section{RESUMO}

Questões voltadas para o encadeamento de relações em que a pertinência dos indicadores ganha sentido e legitimação - tais como as condições sociais de produção, difusão, reprodução e transformação foram abordadas com vistas a introduzir uma discussão teórico-metodológica que abarque a construção de indicadores psicossociais. Ao adotar a teoria das representações sociais, o estudo identificou que sua fecundidade para o desenvolvimento de avaliações educacionais ainda é insuficientemente explorada, apesar de o fenômeno das representações sociais conter o ato de avaliar. Nesse sentido, a proposição de adoção de um paradigma psicossocial para a elaboração de indicadores avaliativos no âmbito educacional foi entendida a partir de um novo ethos, bem como de uma renovada postura epistêmica, sem desconsiderar o rigor e a seriedade indispensáveis às pesquisas avaliativas. 


\section{INDICADORES PSICOSOCIALES: UNA MIRADA AMPLIADA A LOS PROCESOS EDUCATIVOS}

RESUMEN

Cuestiones relacionadas con el encadenamiento de relaciones en que la pertinencia de los indicadores gana sentido y legitimación - como las condiciones sociales de producción, difusión, reproducción y transformación - fueron abordadas con miras a introducir una discusión teórico-metodológica a fin de abarcar la construcción de indicadores psicosociales. Al adoptar la teoría de las representaciones sociales, el estudio identificó que su fecundidad para el desarrollo de evaluaciones educacionales todavía es insuficientemente explotada, a pesar de que el fenómeno de las representaciones sociales contenga el acto de evaluar. En este sentido, la proposición de adopción de un paradigma psicosocial para elaborar los indicadores evaluativos en el ámbito educacional fue entendida desde un nuevo ethos, así como la adopción de una postura epistémica, sin desconsiderar el rigor y la seriedad indispensables a las investigaciones evaluativas.

PALABRAS CLAVE INDICADORES PSICOSOCIALES - EVALUACIÓN DE LA EDUCACIÓN • REPRESENTACIONES SOCIALES • PSICOLOGÍA SOCIAL.

\section{PSYCHOSOCIAL INDICATORS: A WIDE VIEW OF EVALUATION PROCESSES}

ABSTRACT

Questions associated with the binding of relations, in which the pertinence of indicators gain meaning and legitimization such as social conditions of production, promotion, reproduction and transformation, were raised in order to present a theoretic-methodological discussion about the construction of psychosocial indicators. Adopting the theory of social representations, the study identified that its contribution to the development of educational evaluation is insufficiently explored, even if the phenomenon of social representations is suitable to assess it. In this respect, the proposal to adopt a psychosocial paradigm with the aim of elaborating evaluation indicators in the educational context was understood from a new ethos, as well as from a renewed epistemic attitude, without ignoring the necessary rigor and seriousness for the studies.

KEYWORDS PSYCHOSOCIAL INDICATORS - EDUCATION EVALUATION • SOCIAL REPRESENTATIONS • SOCIAL PSYCHOLOGY. 


\section{INTRODUÇÃO}

As abordagens avaliativas que tiraram a tônica do sujeito social simbolizante afetaram a área de educação, que se orientou sobretudo pela visão dominante centrada nos observáveis. ${ }^{1} \mathrm{Tal}$ paradigma guiou os estudos que, ao desconsiderarem os sujeitos sociais enquanto agentes de suas próprias circunstâncias, deixaram de ter em conta inúmeros condicionantes que permitiriam uma hermenêutica mais holística dos contextos educacionais, de maneira a contribuir para a efetividade da proposição de ações decorrentes das avaliações educacionais.

Com vistas a debater tal problemática, o presente texto foi organizado em três seções. Inicialmente, buscou abordar questões voltadas para o encadeamento de relações em que a pertinência dos indicadores ganha sentido e legitimação, com vistas a introduzir uma discussão teórico-metodológica que abarque a construção de indicadores psicossociais - tais como as condições sociais de produção, difusão, reprodução e transformação.

Em seguida, do artigo consta um breve debate acerca da fecundidade da teoria das representações sociais para o 
desenvolvimento de avaliações educacionais, resultante da constatação de que, apesar de o fenômeno representacional conter o ato de avaliar, tal perspectiva teórica ainda é insuficientemente explorada no que tange à elaboração de indicadores psicossociais.

Por fim, foi apresentada uma experiência avaliativa, com o intuito de ilustrar a adoção desse paradigma psicossocial para a elaboração de indicadores no âmbito educacional. Tal adoção foi entendida como uma renovada postura epistêmica, sem desconsiderar o rigor e a seriedade indispensáveis às pesquisas avaliativas.

\section{CONTEXTUALIZAÇÃO DE UM CONCEITO}

Haja vista o intuito de colocar foco sobre os indicadores, parece importante oferecer uma definição etimológica do termo indicador, que, segundo Houaiss, Vilar e Franco (2001), tem procedência do latim indicare, cujo significado reside em "que ou o que indica”, em outras palavras, mostrar, demonstrar, revelar ou trazer uma informação ao conhecimento público.

Nessa direção, Figari (1996, p. 110) observa que a noção de indicador, em sua origem, "trata de um elemento que mostra um outro elemento, que diz onde se encontra um outro elemento, que indica." Em outros termos, tem o sentido de sinal ou índice, sendo que, em matéria de conhecimento, provém da experiência. O autor analisa, citando Barbier (1985), que os indicadores podem ser considerados como representativos da realidade a ser estudada; agrupam categorias de informações que apresentam um interesse axiológico e ganham indiretamente significado em relação a um conjunto de fins e valores, aspectos esses que remetem à noção de critério.

Por sua vez, a palavra critério, conforme salientado por Figari (1996), originária do latim, criterium, designa o princí-

pio que permite distinguir o verdadeiro do falso, em outros termos, julgar, e que tem como característica a abstração. Embasado em Ardoino e Berger (1989), o autor compreende que o critério desempenha o papel de interface, por um lado, das visões de mundo e, por outro, entre os índices, os 
indicadores mais operatórios. Assim sendo, os critérios constituem os referentes, que evidenciam objetivos/expectativas a serem perseguidos, e os indicadores são os referidos, expressando os dados observáveis que permitem dizer se o objeto responde ao critério.

Os indicadores também podem ser vistos como alternativas metodológicas construídas subjetivamente, que permitem gerar informações sobre um fenômeno, apresentando-se como uma medida com dupla função: mostrar/descrever e valorar informações. Nesse tocante, pode-se afirmar que os indicadores procuram retratar a operacionalização de conceitos, muitas vezes abstratos, e, com isso, atender às demandas de distintas áreas temáticas da realidade social. São considerados essenciais para as atividades de avaliação e monitoramento, pois permitem informar aspectos da realidade social ou sobre as transformações que estão se processando.

A título de ilustração, os indicadores podem: ajudar a evidenciar o estado de saúde da população de uma determinada região; oferecer informações sobre a estrutura etária, esboçar perspectivas de crescimento, registrar migrações e mortalidade; medir o avanço da sociedade e o desempenho da gestão pública; delinear um cenário da qualidade ambiental e dos recursos naturais (além de descrever as tendências ambientais, associando-as ao desenvolvimento sustentável); verificar a situação de determinada área da macroeconomia (inflação, taxa de desemprego e médias salariais, dentre outras). Além disso, permitem medir a disponibilidade, o acesso e o grau de utilização de bens, serviços e conhecimentos, assim como possibilitam captar a intensidade de processos e sentido de mudanças.

Apesar de o presente estudo não ter se dedicado a um exame exaustivo das origens dos indicadores, uma breve retomada histórica evidenciou uma matriz inicial segundo a qual seu desenvolvimento e uso residiam sob o domínio de cientistas econômicos, com predomínio da quantificação. Porém, a partir de 1920 e especialmente após a $2^{\text {a }}$ guerra mundial, houve um reconhecimento do esgotamento de tais indicadores para explicar as transformações e condições sociais da população, o que abriu espaço para o alargamento dos indicadores sociais (SOLIGO, 2012). 
Conforme registra Jannuzzi (2001), embora tenha havido algumas contribuições anteriores, a construção do marco conceitual sobre indicadores sociais ocorreu na década de 1960, com esforço metodológico para o desenvolvimento de instrumentos de mensuração do bem-estar social e da mudança social. ${ }^{2}$ Como superação dos insucessos da década de 1970, advindos da adoção de modelos tecnocráticos, nos anos 1980, houve o aprimoramento de novas experiências para implementação de políticas, restabelecendo-se a pertinência dos indicadores. $\mathrm{O}$ autor assim define indicador social:

É uma medida geral quantitativa adotada de significado social substantivo, usado para subsidiar, quantificar ou operacionalizar um conceito social abstrato, de interesse teórico (para pesquisa acadêmica) ou pragmático (para formulação de políticas). É um recurso metodológico empiricamente referido, que informa algo sobre um aspecto da realidade social ou sobre mudanças que estão se processando na mesma. (JANNUZZI, 2001, p. 15)

Em outros termos, os indicadores chamados sociais são utilizados para medir ou evidenciar aspectos relacionados a diversos planos da vida social, que se constituem como realidades complexas nas quais muitos fatores e sujeitos atuam, intervêm e moldam as relações e processos. Considerando tais aspectos, Valarelli (2004) salienta que os indicadores se referem a elementos tangíveis e intangíveis da realidade. Entende como tangíveis aqueles facilmente observáveis e aferíveis, como renda, escolaridade, saúde, organização, gestão, conhecimentos, habilidades, formas de participação, legislação, entre outros, e como intangíveis aqueles que se permitem a captação parcial e indiretamente de algumas manifestações, como consciência social, autoestima, valores, atitudes, liderança, poder, cidadania. ${ }^{3}$

Segundo o autor, a eleição de um sistema de indicadores referente a múltiplas dimensões do fenômeno social deve considerar a presença de concepções, interesses e modos de gestão do lócus do fenômeno, o que envolve distintas visões das questões sociais, diferentes valores, objetivos e expectativas, aspectos esses que requerem negociações. Além disso,
2 Destaque feito à participação de organizações multilaterais, entre elas a Organização para a Cooperação e Desenvolvimento Econômico (OCDE), a Organização das Nações Unidas para a Educação, a Ciência e a Cultura (Unesco), a Organização das Nações Unidas para Agricultura e Alimentação (FAO), a Organização Internacional do Trabalho (OIT), a Organização Mundial de Saúde (OMS), o Fundo das Nações Unidas para a Infância (Unicef).

3 Neste caso, dada a complexidade das dimensões da realidade, é demandado um conjunto de indicadores que, por aproximações, capturam as manifestações. 
deve ser considera a especificidade do contexto, o que exige um diagnóstico situacional.

Os indicadores sociais podem ser classificados, como aponta Jannuzzi (2001), segundo as diversas aplicações a que se destinam. A classificação mais comum é a divisão dos indicadores segundo a área temática da realidade social a que se referem, definindo-se assim indicadores de saúde, indicadores educacionais, indicadores demográficos, indicadores habitacionais, indicadores de segurança pública e justiça, indicadores de infraestrutura urbana e indicadores de renda e desigualdade.

O estudo aqui relatado teve como foco os indicadores educacionais e, particularmente, os indicadores considerados no âmbito da avaliação educacional, ao entender que os indicadores são partes constituintes do trabalho avaliativo, pois orientam o processo de coleta e processamento de informações com vistas a comparar resultados, emitir um julgamento de mérito ou valor e orientar tomada de decisões.

Essa compreensão ampliada da avaliação educacional, em seus usos e definições, tem sua justificativa apoiada em um processo histórico relativamente recente, constituído nos últimos 60 anos. Nesse tocante, a dimensão temporal do conceito de avaliação precisa ser compreendida numa perspectiva genética que se retroalimenta, uma vez que a trajetória do trabalho intencional ocorreu no cruzamento de protagonistas e objetos avaliados.

Tal história pode ser sintetizada em quatro etapas geracionais distintas, assim nomeadas: a) Avaliação associada à medida; b) Avaliação com referência a objetivos; c) Avaliação como juízo de valor; e d) Avaliação como processo de negociação e construção (GUBA; LINCOLN, 1989; HADJI, 1994). Embora haja uma compreensão de evolução na direção da primeira à quarta etapa, cada uma ainda se mantém guiando as práticas avaliativas, o que remete a uma questão de opção epistemológica, que define o pensar e o agir dos sujeitos sociais frente à realidade. ${ }^{4}$

O contexto brasileiro acompanhou o movimento das quatro gerações de avaliação, com passos mais lentos do que o observado no panorama internacional. Uma rápida mirada 
para a realidade educacional, baseada em Sousa (1993), mostra que a avaliação, a partir anos 1950, manteve-se voltada sobretudo para a avaliação do desempenho dos estudantes com base nos objetivos, com grande influência e repercussão da figura de Tyler. ${ }^{5} \mathrm{Na}$ década de 1960 , constatou-se o predomínio da dimensão tecnológica e tecnicista na busca da eficiência. Somente duas décadas depois, a área assumiu a dimensão valorativa, a partir da discussão das dimensões políticas e ideológicas das práticas escolares avaliativas e da discussão da avaliação no contexto do sistema educacional e do sistema social. Por sua vez, nos anos 1990, a avaliação volta-se para a organização escolar, referindo-se a um projeto pedagógico, e se fortalece pela preocupação com os sistemas educacionais e avaliação institucional, elevando o status do processo avaliativo para o aperfeiçoamento de decisões institucionais e orientação de políticas. É, portanto, nesse contexto que se observa um expressivo movimento de preocupação com os indicadores educacionais.

Os diferentes conceitos de avaliação gerados na década de 1990 se justificam sobretudo pela crescente complexidade do sistema educativo como resposta a exigências sociais, na tentativa de legitimar decisões políticas que remetem para aspetos de ordem organizacional e social. Constatou-se o aumento da produção e da análise de indicadores educacionais, impulsionado pelo crescimento econômico brasileiro datado do final dos anos 1920 até o ano de 1980, que levou o país a ingressar no grupo das dez maiores economias do mundo, o que apontou para exigências estruturais para a gestão e a regulação do trabalho educativo.

Para contemplar tais necessidades, foram sendo instalados no Brasil órgãos específicos para gestão educacional e produção de dados educacionais, visando a atender às demandas sociais de acesso à educação de qualidade. No entanto, os indicadores educacionais produzidos desde então têm se mostrado insuficientes para explicar a complexidade da realidade educacional. Verificou-se, por exemplo, que alguns indicadores conduzem à inferência de que a educação brasileira apresentou crescimento lento, porém contínuo, elevando o nível de escolarização da população e diminuindo a
5 Em "Princípios básicos de currículo e ensino", obra publicada originalmente em 1949, Tyler oferece um modelo de elaboração do currículo, destacando a avaliação como constituinte de controle do planejamento. Tal modelo ancorase em perspectiva positivista, ao compreender a avaliação enquanto sinônimo de medida, ao dar tônica à objetividade, sobretudo no que concerne à fiabilidade com valorização matemática. Essas características, aliadas à função e noção de controle e rigor, são elementos que sofreram, ao longo do tempo, uma série de críticas. 
6 Este último refletido nas médias obtidas nos exames nacionais de avaliação, como a Prova Brasil e o Programme for International Student Assessment (PISA) desigualdade entre as regiões e as populações de baixa renda (SILVA, 2003). Por outro lado, diferentes indicadores nos dirigem à constatação de que, no mesmo período, houve a persistência de problemas como atraso escolar e de desempenho (VELOSO, 2011). ${ }^{6}$

Diante de resultados conflitantes, verifica-se a necessidade de serem construídos indicadores que expressem a diversidade da realidade educacional, por meio do investimento em abordagens metodológicas que contribuam para a coleta e a sistematização de informações significativas para os estudos de avaliação e para as demais pesquisas em educação. Significa dizer que os indicadores devem ir além da função de mostrar/descrever, de modo a coletar e valorar informações que estimulem transformações no sentido do aperfeiçoamento das práticas nos contextos educacionais.

Isso se faz necessário, pois a captura das múltiplas facetas que compõem o fenômeno social

[...] não é de maneira alguma uma duplicação da realidade, tampouco é o reflexo de uma infraestrutura à qual pertenceria toda a realidade. É antes um buraco sem fundo, um sol negro que pode cegar. [...] Porém, ao mesmo tempo, a imagem, diferentemente do mecanismo da razão, exprime bem a organicidade profunda de cada coisa. É o que chamei de holismo. É o que explica que seja, ao mesmo tempo, fator de desagregação: a do mecanismo e do racionalismo, próprios da modernidade; e fator de agregação: em torno dela reúne, comunga-se. (MAFFESOLI, 1995, p. 138)

Nesse sentido, a captura do fenômeno social não se restringe às manifestações concretas nem passivas propostas pelas formas tradicionais de descrição de indicadores, pois os mesmos são entendidos como elaborações constituintes do pensamento, sobrepondo-se, alterando-se e transformando-se constantemente (FERREIRA, 2015). Tal compreensão destaca a relevância da consideração da interação social, base do relacionamento humano, em que os membros do grupo repartem suas atividades e interagem. Nesse enfoque é importante levar em conta o potencial dos indicadores, 
que apontam, indicam, aproximam e traduzem em termos operacionais as dimensões sociais que se ajustam aos aspectos fundamentais a serem analisados, ao fenômeno social que se deseja explorar e compreender.

La interacción de los factores sociales, psicológicos y culturales que influyen en las personas, junto con los factores políticos, religiosos, económicos y ambientales que influyen en los programas es increíblemente compleja, y es difícil de conceptuar y analizar. A fin de entender el «por qué» y no solo el «cuanto», es preciso que los evaluadores examinen esta compleja interacción de factores, la cual sólo pueden lograr mediante un planteamiento metodológico de evaluación que integre técnicas cualitativas y cuantitativas para recoger y analizar la información, logrando así, una amplia variedad de datos sobre el programa. (ANDRADE; SHEDLIN; BONILLA, 1987).

Pesquisas que envolvem as áreas de conhecimento da psicologia e da sociologia aproximam fatores estruturantes associados ao comportamento individual e coletivo, bem como aos processos psicológicos. Desse ponto de vista,

La psicología social, en tanto que espacio de intersección de ambas as disciplinas, asumiría como propias aquellas explicaciones del comportamiento humano en las que considera la interacción entre ambos tipos de factores. En definitiva, todas estas reflexiones nos llevan a considerar que la psicología social no viene definida por su objeto de estudio, que es el mismo que el de otras ciencias sociales, sino por el enfoque desde el que dicho objetos analizado, debiendo ser entendida, por tanto como un punto de vista o una perspectiva desde la que estudiar la realidad social. (ÁLVARO; GARRIDO, 2007, p. 9)

Moscovici (1988, p. 16) observa que "a desatenção para o aspecto psíquico dos fenômenos sociais tem como efeito a desatenção com o real, pelo simples fato de que eles são compostos por homens.” Nossas representações, ligações e ideais, diz o autor, fazem a parte indestrutível de toda a vida coletiva e, por isso, em qualquer interpretação, deve coincidir 
7 Tais espaços de interação são entendidos neste artigo como psicossociais. a objetividade da análise histórica com a subjetividade da experiência vivida.

Levar em consideração os espaços de interação entre a psicologia e a sociologia e seu respectivo conjunto de indicadores consiste em realizar a articulação de níveis diferenciados de apontamentos, ${ }^{7}$ indicações, aproximações e explicações capazes de traduzir em termos operacionais as dimensões fundamentais do fenômeno social que se deseja explorar e compreender. Nesse sentido, as teorias psicossociais trazem consigo uma perspectiva integradora, capaz de ajudar e de confrontar diferentes áreas de pesquisa e de avaliação. Como assinala Marcondes (2004), essa composição multidisciplinar tem produzido conhecimentos dos quais derivam categorias fundamentais para estudar os fenômenos humanos que se dão nos espaços públicos. Entre essas categorias, incluem-se, por exemplo, representações sociais, a consciência, a subjetividade, a identidade, a atividade e as emoções.

\section{UM OLHAR PSICOSSOCIAL PARA A AVALIAÇÃO}

Contrária à segregação do sujeito de seu contexto, a abordagem psicossocial da teoria das representações sociais (TRS) permitiu a construção de uma proposta de relevante potencial interdisciplinar (MOSCOVICI, 1961, 1978, 2012). Nas palavras de seu criador,

[...] quando estudamos representações sociais nós estudamos o ser humano, enquanto ele faz perguntas e procura respostas ou pensa e não enquanto processa informação, ou se comporta. (MOSCOVICI, 2003, p. 43)

A educação tem sido uma das disciplinas mais favorecidas por essa perspectiva, uma vez que a teoria das representações sociais oferece um frutífero instrumental para a análise das significações nos âmbitos educacionais. Apesar do já consolidado campo de estudos em representações sociais e educação, ${ }^{8}$ nas pesquisas avaliativas, sobretudo no que concerne à construção dos indicadores, é possível identificar a prevalência das medidas quantitativas em detrimento 
daquelas que dão ênfase às simbolizações circulantes entre os respondentes.

Ao compreender que "as avaliações afetam as concepções e avaliações da relação pedagógica e das aquisições que as possibilitam" (JODELET, 2007, p. 13), o presente estudo foi sustentado pela assertiva de que as significações podem ser apreendidas por meio de pesquisas avaliativas que considerem as expressões dos agentes de diferentes contextos em relação às posições sociais que ocupam, a exemplo do discurso das políticas públicas, dos discursos e das ações dos gestores educacionais, do discurso e das práticas dos professores e funcionários, bem como dos estudantes, da família e da comunidade.

No intuito de compreender as simbolizações e significações de pessoas e grupos, a teoria das representações sociais propõe um olhar sobre os sujeitos e suas interações ao rechaçar a falsa antinomia entre indivíduo e sociedade. ${ }^{9}$ Nessa perspectiva teórica, a existência pessoal é destacada pela convivência com os demais sujeitos sociais. Significa dizer que, ao adotar a perspectiva psicossocial para o desenvolvimento de um processo avaliativo, passamos a ser tributários de um paradigma distinto daquele que orientou a ciência e, por conseguinte, a avaliação moderna (SOUSA; NOVAES, 2013).

Em outros termos, uma avaliação que se pretende psicossocial é caracterizada por um ethos que reconhece em todos os envolvidos a potencialidade de construção de um saber e do exercício consciente de ações no contexto avaliado. Nesse tocante, Marková, ao discorrer sobre as implicações éticas das investigações em representações sociais, destaca que:

Escalas de opinião e atitude, questionários acerca de atribuições, estereótipos, preconceitos ou influências - todos têm como objetivo examinar fatos e categorias, informações e o pensamento racional dos cidadãos, como se os participantes em tais estudos fossem máquinas racionalizadas que expressam pensamentos sem qualquer envolvimento ativo relativamente a tais fenômenos socialmente valorizados. (MARKOVÁ, 2015, p. 86)

Ao adotar os constructos de uma abordagem psicossocial que assume a indissociabilidade entre o psicológico e o
9 Jovchelovitch (2008, p. 87) assim sintetiza: "As representações sociais se referem tanto a uma teoria quanto a um fenômeno, elas são uma teoria que oferece um conjunto de conceitos articulados que buscam explicar como os saberes sociais são produzidos e transformados em processos de comunicação e interação social. Elas são um fenômeno que se refere a um conjunto de regularidades empíricas, compreendendo as ideias, os valores e as práticas de comunidades humanas sobre objetos sociais específicos, bem como sobre os processos sociais e comunicativos que os produzem e reproduzem". 
10 Para Jovchelovitch (2008, p. 37-38 grifos do original): "E com base na função simbólica das representações - o fato de que a representação usa símbolos para significar, para dar sentido ao real e ao mesmo tempo estabelecê-lo - que podemos compreender tanto seu poder de construir a realidade como as limitações de concepções empiricistas que assumem a existência de ordens empíricas como um a priori aos trabalhos da cognição humana".

11 Os dois processos de elaboração de representações, objetivação e ancoragem, dizem particularmente respeito à referida dimensão avaliativa, haja vista que ancorar é precisamente classificar e dar nome a alguma coisa e "objetivar é descobrir a qualidade icônica de uma ideia, $[$... é reproduzir um conceito em uma imagem" (MOSCOVICl, 2003, p.71) social para a elaboração de indicadores avaliativos, procurou-se maiormente evitar o risco de culpabilizar indivíduos e grupos por problemas sociais de grande espectro (como comumente são os da educação), bem como desviar da valorização das superestruturas, quando desarticuladas das dimensões subjetivas.

Trata-se, portanto, da assunção de um ethos singular que guia o processo avaliativo, visto que, nesse paradigma, o saber de avaliadores, especialistas e leigos (no que concerne às relações intersubjetivas e interobjetivas) são entendidos como legítimos, rejeitando-se a hierarquização do conhecimento, uma vez que,

[...] acerca de todos os objetos, a representação está numa relação de simbolização: vem em seu lugar e ao mesmo tempo é o produto de uma construção da parte do sujeito que faz uma interpretação em função de suas capacidades cognitivas, de suas necessidades psicológicas, de seus constrangimentos sociais, dando significações específicas ao objeto de representação. (JODELET, 2007, p. 15)

Significa dizer que a empreitada aqui relatada considerou a análise do simbólico enquanto um contributo para a compreensão do sentido de uma representação, assim como para o estudo das suas consequências no mundo social, ${ }^{10}$ uma vez que o ato de representar possui uma dimensão avaliativa que, ${ }^{11}$ em companhia de outras, colabora para a elaboração de seus elementos informativos, cognitivos, ideológicos, formativos, bem como para as crenças, valores, atitudes, opiniões e imagens que a compõem. Nas palavras de Moscovici (2003, p. 62):

De fato, representação é, fundamentalmente, um sistema de classificação e de denotação, de alocação de categorias e nomes. A neutralidade é proibida, pela lógica mesma do sistema, onde cada objeto e ser devem possuir um valor positivo ou negativo e assumir um determinado lugar em uma clara escala hierárquica.

A fecundidade da TRS para a avaliação educacional é ainda insuficientemente explorada, apesar do entendimento 
de que o fenômeno das representações sociais encerra em si o ato de avaliar, motivo pelo qual buscou-se, por meio de um estudo avaliativo de caráter exploratório, iniciar uma empreitada no sentido de refinar os procedimentos de elaboração de indicadores psicossociais.

\section{À GUISA DE ILUSTRAÇÃO: UM EXEMPLO DE CONSTRUÇÃO DE INDICADORES PSICOSSOCIAIS}

A Figura 1, que segue, aproxima conceitos e organiza possibilidades para a exploração e a reflexão sobre o processo teórico-metodológico que busca abarcar a construção de indicadores psicossociais.

FIGURA 1 - Imagem da composição de indicadores psicossociais

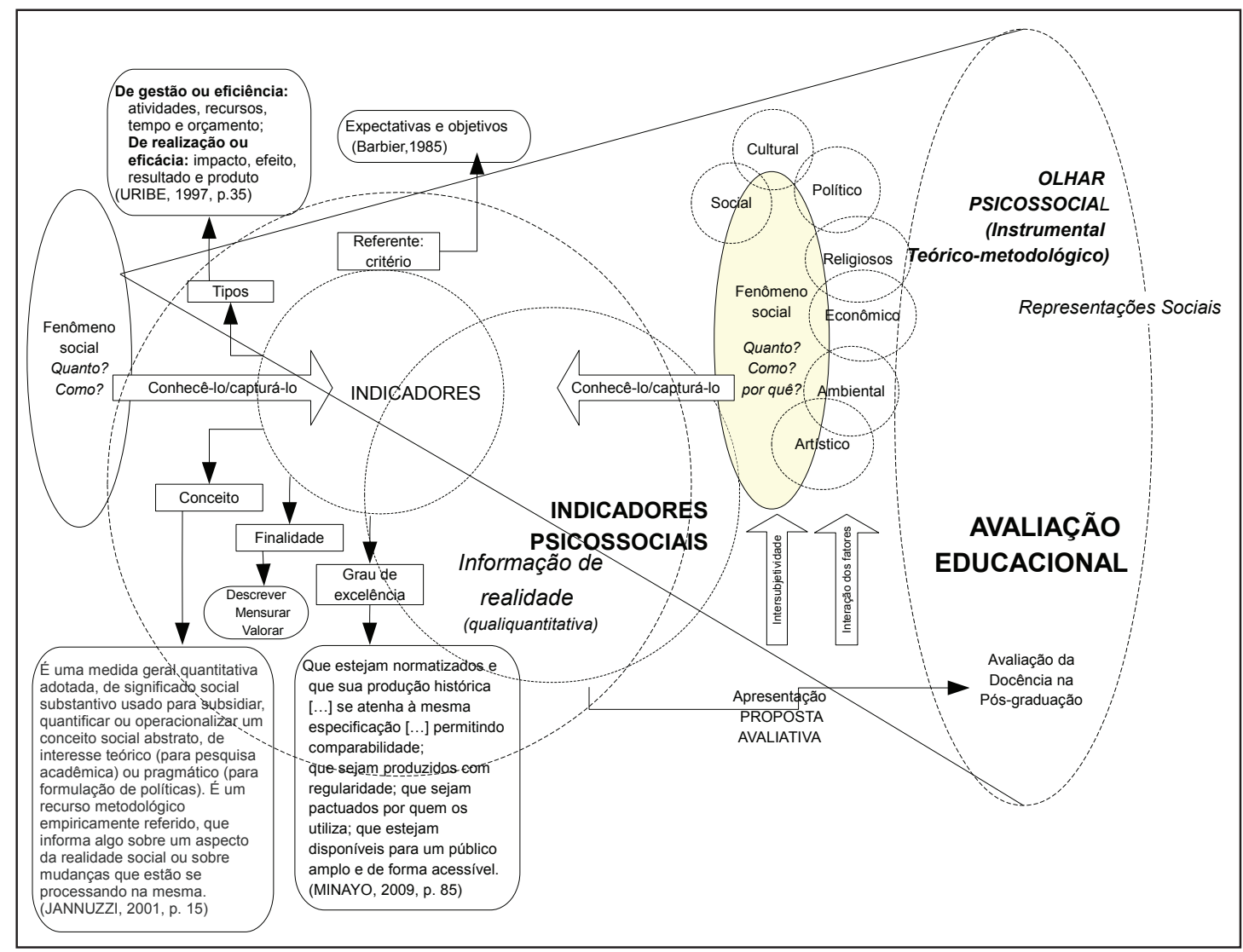

Fonte: Elaboração das autoras. 
Foi com base em tal diagrama que o trabalho avaliativo aqui descrito desenvolveu-se. Ao se inserir no contexto da avaliação da docência, numa perspectiva formativa, a trajetória investigativa assumiu como objetivo explorar as imagens e os significados que professores e estudantes da pós-graduação compartilham acerca do docente em sala de aula, bem como no processo de orientação, e, para tal, elaboraram-se indicadores de avaliação da docência.

Minayo (2009), em sua análise relativa à construção de indicadores de avaliação em contextos educacionais, salienta a importância de os pesquisadores buscarem se aproximar do universo cultural dos atores que avaliam, para expressar a voz, os sentimentos, os pensamentos e as práticas que compõem o universo pesquisado. A autora ainda destaca que a validade interna desses indicadores pode ser alcançada quando as categorias conceituais empregadas possuem significados mútuos e partilhados entre os participantes, a partir de um processo de construção em que se assegura fundamentação teórica e contextual.

Tais aspectos foram considerados na avaliação da docência, que se constitui uma temática amplamente discutida, uma vez que a compreensão da prática docente passa pela consideração de um objeto social, culturalmente construído e em constante transformação, pressupondo diferentes vozes fundamentadas em distintas leituras e interpretações. Um estudo com tal pretensão requer, portanto, a compreensão do modo como os sujeitos se veem enquanto docentes e como os outros os veem, sobretudo os estudantes, tendo em vista a dimensão social e intersubjetiva dos sentidos e significados ativados nos contextos de interação.

Diante desses desafios, a discussão firmou-se na perspectiva psicossocial da teoria das representações sociais, uma vez que a tradição teórico-metodológica dessa abordagem favorece o estudo dos sistemas de saberes compartilhados pelos sujeitos sociais, dos processos simbólicos dos grupos envolvidos e das relações estabelecidas com um objeto social: a prática docente.

Manifestar-se sobre a avaliação da docência oferece elementos que ou expressam um discurso pedagógico, de caráter normativo, muitas vezes incompatível com a vivência 
cotidiana, ou se restringem e reforçam cognições e crenças que, fossilizadas, deixaram de ser questionadas. Assim sendo, como encaminhamento metodológico, professores e pós-graduandos foram chamados a se envolver no processo de construção de indicadores para a avaliação da docência na pós-graduação. Para tanto, optou-se pela coleta de informações por meio de um questionário (Q1) on-line, com itens dissertativos, que foi respondido por 114 professores e 427 estudantes de pós-graduação stricto sensu de uma instituição de educação superior da cidade de São Paulo. O instrumento continha três itens dissertativos, a saber:

QUADRO 1 - Itens do questionário de avaliação \begin{tabular}{l} 
Prezados, visando ao aperfeiçoamento do processo de Avaliação da Docência na \\
Pós-Graduação, [...] solicitamos sua manifestação em relação aos itens a seguir: \\
\hline $\begin{array}{l}\text { 1- Quais aspectos deveriam ser considerados para avaliação do desempenho do } \\
\text { professor de pós-graduação em sala de aula? }\end{array}$ \\
\hline $\begin{array}{l}\text { - Quais aspectos deveriam ser considerados para a avaliação do desempenho } \\
\text { dos orientandos de dissertação ou tese? }\end{array}$ \\
\hline $\begin{array}{l}3 \text { - Registre aqui outros comentários que contribuam para a avaliação da docência } \\
\text { na pós-graduação. }\end{array}$ \\
\hline
\end{tabular} Fonte: Elaboração das autoras.

Para tratamento e interpretação das informações, recorreu-se ao software Analyse Lexicale par Contexte d'un Ensemble de Segments de Texte (Alceste) e aos procedimentos da análise de conteúdo (BARDIN, 2011; FRANCO, 2012). O programa computacional produziu um relatório informatizado dos conteúdos discursivos. Tal relatório descreveu as análises hierárquicas processadas a partir do corpus inicial - conjunto de respostas e ofereceu contextos textuais que compõem as classes de palavras (que consistem na expressão estável e coletiva dos respondentes). Com base em Secchi, Camargo e Bertoldo (2009), as classes de palavras foram compreendidas como categorias temáticas dos sentidos atribuídos pelos sujeitos consultados e puderam oferecer indícios de representações sociais que, combinados a outros resultados, contribuíram para a compreensão das simbolizações circulantes no contexto investigado.

A análise das respostas dos professores esboçou quatro diferentes classes ou blocos de sentidos, envolvendo a docência: 1) Especificidades do profissional professor de pós-graduação 
12 ○ qui-quadrado é utilizado nesta pesquisa, pois seus valores revelam quantitativamente a relação entre os produtos da pesquisa - no caso, a análise das respostas dos professores - e a distribuição prevista para o fenômeno.
(44\% das unidades de contexto elementar - UCE); 2) Produção de conhecimento: sujeito e orientador (14\%); 3) Docência e orientação: responsabilidades (30\%); e 4) Relação com o estudante e compromisso (12\%). Para as respostas dos estudantes, também foram geradas quatro classes ou blocos de sentido: 1) Orientação: acompanhamento, auxílio e controle (30\%); 2) Docência na sala de aula: conhecimento, atualização, didática e disponibilidade (35\%); 3) Especificidades da avaliação do docente da pós-graduação $(21 \%$ das UCE); e 4) Produção de conhecimento: professor incentivador e parceiro (14\%). Para todas as oito classes, a exploração foi organizada e apresentada por seu vocabulário (por ordem de frequência de ocorrência) e pela indicação da significação da sua ligação com a classe (qui-quadrado). ${ }^{12}$ Esses oito blocos de sentido compuseram uma matriz avaliativa de indicadores que se constituiu como base para a construção de um instrumento de avaliação.

A análise das respostas dos professores esboçou que os mesmos apresentam uma imagem da docência em que prevalece a condição do especialista na área, produtor de conhecimento, indicando para uma representação bastante consolidada de um professor de pós-graduação. Além disso, os docentes pesquisados destacam a necessidade de investimentos na autonomia dos estudantes resultante de um processo relacional. As informações coletadas junto aos pós-graduandos compõem a imagem da docência com elementos voltados para acompanhamento, disponibilidade, auxílio e controle da sua produção. Têm expectativas de um docente incentivador da produção e da divulgação do conhecimento em parceria com o estudante.

A confrontação dos resultados dos dois grupos investigados indica um afastamento entre a expectativa do processo relacional na prática pedagógica: por um lado, os docentes revelam uma preocupação com a autonomia dos estudantes e estes, por outro lado, demandam maior dependência.

Da experiência relatada, salienta-se que os resultados permitiram a elaboração de indicadores para a construção de um instrumento da avaliação da docência que, distanciando-se de um enfoque avaliativo predominantemente assentado em medidas de ordem numérica, permitiria o desenvolvimento e o fortalecimento de um trabalho avaliativo/formativo. 


\section{CONSIDERAÇÕES FINAIS}

A demanda pelo uso de indicadores psicossociais em processos avaliativos é sofisticada e exigente, uma vez que espaços de intersubjetividade são irrigados por conflitos e dilemas gerados, muitas vezes, pela incompatibilização entre expectativas, condições de realidade e também pela presença de valores que orientam ações e relações com o outro, entrelaçando, (re)criando e atribuindo sentidos à realidade.

Captar a complexidade dos espaços de trocas simbólicas demanda uma leitura diferenciada da realidade, de modo a reconhecer as contradições, os componentes fragmentados, impregnados de emoções e ambiguidades. A compreensão implica, portanto, ir além da preocupação com a relação causal, com descrever e mesmo explicar, pois envolve valoração, significação e relevâncias em contextos de interação.

Foi nesse sentido que o presente artigo buscou iniciar um debate acerca do planejamento de processos avaliativos, calcados na perspectiva psicossocial da teoria das representações sociais, uma vez que tal abordagem permite o reconhecimento, em todos os envolvidos, da potencialidade de construção de um saber transformador e do exercício consciente de ações no contexto avaliado.

Tal perspectiva oferece condições para a construção de indicadores, aqui compreendidos como psicossociais, que contribuam para ampliar a compreensão da realidade educacional, ao estimular mudanças, aperfeiçoamento de práticas e a emergência de sujeitos instituintes. Nesse sentido, a proposição de adoção de um paradigma psicossocial na elaboração de indicadores avaliativos no âmbito educacional foi entendida a partir de um novo ethos, bem como de uma renovada postura epistêmica, sem desconsiderar o rigor e a seriedade das pesquisas avaliativas. Trata-se, em última instância, de uma esperança revigorada no potencial político e na capacidade de transformação de ações por meio da avaliação educacional. 


\section{REFERÊNCIAS}

ÁLVARO, J. L.; GARRIDO, A. Psicologia social: perspectivas psicológicas e sociológicas. São Paulo: McGraw-Hill, 2007.

ANDRADE, S.; SHEDLIN, M.; BONILLA, E. Métodos cualitativos para la evaluación de programas: un manual para programas de salud, planificación familiar y servicios sociales. Watertown, MA: The Pathfinder Fund, USA, 1987.

ARDOINO, J.; BERGER, G. D'une évaluation em miettes à une évaluation en actes. Andsha: Matrice, 1989.

BARBIER, J. M. L'évaluation en formation. Paris: PUF, 1985.

BARDIN, L. Análise de conteúdo. Lisboa: Edições 70, 2011.

CHAIB, M. Social representations, subjectivity and learning. Cadernos de Pesquisa, São Paulo, v. 45, n. 156, p. 358-372, abr.jjun. 2015. Disponível em: <http://www.scielo.br/scielo.php?script=sci_arttext\&pid=S0100$15742015000200358 \& \operatorname{lng}=$ en\&nrm=iso> Acesso em: jun. 2016.

FERREIRA, S. L. Imagens de escola e as representações sociais. Curitiba: CRV, 2015.

FIGARI, G. Avaliar: que referencial? Porto: Porto, 1996.

FRANCO, M. L. P. B. Análise de conteúdo. Brasília, DF: Liber Livro, 2012.

GILLY, M. As representações sociais no campo da Educação. In: JODELET, D. (Org.). As representações sociais. Rio de Janeiro: Eduerj, 2001. p. 321-341.

GUBA, E. G.; LINCOLN, Y. S. Fourth Generation Evaluation. Texas: Sage, 1989.

HADJI, C. A avaliação, regras do jogo. Das intenções aos instrumentos. 4. ed. Porto: Porto, 1994.

HELLER, A. 0 cotidiano e a história. Petrópolis, RJ: Paz e Terra, 1970.

HOUAISS, A.; VILAR, M. S.; FRANCO, F. M. M. Dicionário Houaiss da língua portuguesa. 1. ed. Rio de Janeiro: Instituto Antônio Houaiss de Lexicografia, 2001. p. 2914-2922.

JANNUZZI, P. M. Indicadores sociais no Brasil: conceitos, fontes de dados e aplicações. Campinas, SP: Alínea, 2001.

JODELET, D. Contribuições das representações sociais para as análises entre educação e trabalho. In: PARDAL, L.; MARTINS, A.; SOUSA, C.; DUJO, Á.; PLACCO, V. (Org.). Educação e trabalho: representações, competências e trajetórias. Aveiro, PT: Universidade de Aveiro, 2007. p. 11-25.

JOVCHELOVITCH, S. Os contextos do saber: representações, comunidades e cultura. Petrópolis, RJ: Vozes, 2008.

MAFFESOLI, M. A contemplação do mundo. Porto Alegre: Artes e Ofícios, 1995.

MARCONDES, A. P. A avaliação institucional do ensino superior: uma análise psicossocial. 239f. Tese (Doutorado e Psicologia da Educação) - Pontifícia Universidade Católica de São Paulo, São Paulo, 2004. 
MARKOVÁ, I. Ética na teoria das representações sociais. In: JESUÍNO, J. C.; MENDES, F. R. P.; LOPES, M. J. (Org.). As representações sociais nas sociedades em mudança. Petrópolis, RJ: Vozes, 2015.

MINAYO, M. C. S. Construção de indicadores qualitativos para avaliação de mudanças. Revista Brasileira de Educação Médica, Rio de Janeiro, v. 33, p. 83-91, 2009. Suplemento 1. Disponível em: <http://www.scielo.br/pdf/rbem/v33s1/ a09v33s1.pdf >. Acesso em: mar. 2016.

MOSCOVICI, S. La psychanalyse, son image et son public. Paris: PUF, 1961.

MOSCOVICI, S. A representação social da psicanálise. Rio de Janeiro: Zahar, 1978.

MOSCOVICI, S. A máquina de fazer deuses. Rio de Janeiro: Imago, 1988.

MOSCOVICI, S. Representações sociais: investigações em psicologia social. Petrópolis, RJ: Vozes, 2003.

MOSCOVICI, S. A psicanálise, sua imagem e seu público. Petrópolis, RJ: Vozes, 2012.

SECCHI, K.; CAMARGO, B. V.; BERTOLDO, R. B. Percepção da imagem corporal e representações sociais do corpo. Psicologia: Teoria e Pesquisa, Brasília, DF, v. 25, n. 2, p. 229-236, abr./jun. 2009. Disponível em: <http:// dx.doi.org/10.1590/S0102-37722009000200011>. Acesso em: maio 2016.

SEIDMANN, S. Identidad personal y subjetividad social: educación y constitución subjetiva. Cadernos de Pesquisa, São Paulo, v. 45, n. 156,

p. 344-357, abr.jjun. 2015. Disponível em: <http://dx.doi. org/10.1590/198053143204>. Acesso em: 28 de jun. 2016.

SILVA, N. V. Expansão escolar e estratificação educacional no Brasil. In: SILVA, N. do V.; HASENBALG, C. (Ed.). Origens e destinos: desigualdades sociais ao longo da vida. Rio de Janeiro: Topbooks, 2003. p. 105-138.

SOLIGO, V. Indicadores: conceito e complexidade do mensurar em estudos de fenômenos sociais. Estudos em Avaliação Educacional, São Paulo v. 23, n. 52, p. 12-25, maio/ago. 2012.

SOUSA, C. P. Avaliação do rendimento escolar. Campinas, SP: Papirus, 1993.

SOUSA, C. P.; NOVAES, A. O. A compreensão de subjetividade na obra de Moscovici. In: ENS, R. T.; VILLAS BÔAS, L. P. S.; BEHRENS, M. A. (Org.). Representações sociais: fronteiras, interfaces e conceitos. 1. ed. Curitiba: Champagnat; São Paulo: Fundação Carlos Chagas, 2013. v. 1. p. 21-36.

SOUSA, C. P.; NOVAES, A. O.; VILLAS BÔAS, L. P. S. Representações sociais e educação: panorama dos estudos desenvolvidos pela cátedra Unesco sobre profissionalização docente. Educação \& Linguagem, São Bernardo do Campo, SP, v. 15, n. 25, p. 19-39, jan./jun. 2012. Disponível em: <https://www.metodista.br/ revistas/revistas-ims/index.php/EL/article/view/3346>. Acesso em: maio 2017.

SOUSA, C. P.; VILLAS BÔAS, L. P. S.; NOVAES, A. O. Contribuições dos estudos de representações sociais para a compreensão do trabalho docente. In: ALMEIDA, A. M. O.; SANTOS, M. F. S.; TRINDADE, Z. A. (Org.). Teoria das representações sociais: 50 anos. 1. ed. Brasília, DF: Technopolitik, 2011. v. 1, p. 625-652. 
TYLER, R. W. Basic principles of curriculum and instruction. Chicago: The University of Chicago Press, 1949.

URIBE, V. M. Evaluación de proyectos sociales construcción de indicadores. Cali: Fundación FES, 1997.

VALARELLI L. L. Indicadores de resultados de projetos sociais. 2004. Disponível em: $<$ https://www.fcm.unicamp.br/fcm/sites/default/files/valarelli_indicadores_ de_resultados_de_projetos_sociais.pdf > Acesso em: fev. 2016.

VELOSO, F. A evolução recente e propostas para a melhoria da educação no Brasil. In: BACHA, E.; SCHWARTZMAN, S. (Org.). Brasil: a nova agenda social. Rio de Janeiro: LTC, 2011. p. 213-253.

VILLAS BÔAS, L.; NOVAES, A. O. Apresentação: representações sociais e desafios contemporâneos. Cadernos de Pesquisa, São Paulo, v. 45, n. 156, p. 240-242, abr./jun. 2015. Disponível em: <http://dx.doi. org/10.1590/198053140060>. Acesso em: 28 jun. 2016.

SANDRA LÚCIA FERREIRA

Professora do Programa de Mestrado Acadêmico em Educação e do Mestrado Profissional "Formação de Gestores Educacionais” da Universidade Cidade de São Paulo (Unicid), São Paulo, São Paulo, Brasil

07sandraferreira@gmail.com

\section{ANAMÉRICA PRADO MARCONDES}

Avaliadora institucional na Pontifícia Universidade Católica de São Paulo (PUC-SP), São Paulo, São Paulo, Brasil apradomarcondes@gmail.com

\section{ADELINA NOVAES}

Pesquisadora do Departamento de Pesquisas Educacionais da Fundação Carlos Chagas; Professora do Programa de Mestrado Acadêmico em Educação e do Mestrado Profissional "Formação de Gestores Educacionais" da Universidade Cidade de São Paulo (Unicid), São Paulo, São Paulo, Brasil anovaes@fcc.org.br 
